\title{
REFORMAS, TRABALHO E IDENTIDADES DOCENTES
}

\author{
REFORMS, WORK AND TEACHING IDENTITIES
}

\author{
N. C. DOS S. LEMES ${ }^{1}$, K. A. DE MELO ${ }^{1}$ e B. BORGES ${ }^{1 *}$
}

${ }^{1}$ Universidade Federal de Goiás, Programa de Pós-Graduação em Educação, Goiânia, Goiás, Brasil

\section{ARTICLE INFO}

Article history:

Received 2018-07-02

Accepted 2018-08-17

Available online 2018-08-31
Palavras-chave: Educação. Trabalho docente. Identidade. Reformas educacionais.

Keywords: Education. Teaching work. Identity. Educational reforms.

${ }^{*}$ Autor correspondente:

E-mail: brunoborgesudi@gmail.com

RESUMO. As mudanças ocorridas no mundo do trabalho nas últimas décadas têm reforçado a necessidade de formação de um novo tipo de trabalhador. A educação, nesse contexto, é colocada como uma área de grande valor estratégico e é apontada tanto como a causa como a solução para os problemas inerentes ao sistema capitalista. Os reformadores empresariais, na ambição de 'consertar' a educação, veiculam um discurso que desqualifica as práticas docentes - consideradas ineficientes, e, ao mesmo tempo, formulam propostas de reformas que visam a alteração do próprio trabalho dos professores e professoras; fatores que abalam a identidade desses profissionais. Por meio de um diálogo com importantes autores da área de trabalho e educação o presente estudo aborda a relação entre o trabalho e a constituição das identidades nas atividades laborais em geral e na docência em particular, além de indicar aspectos de como as transformações no mundo do trabalho e as reformas educacionais das últimas décadas têm induzido alterações nas identidades dos professores e professoras; além disso, demonstra como as reformas vão ao encontro dos interesses dos grupos hegemônicos da sociedade capitalista contemporânea e contra os interesses daqueles que se pautam pela construção de uma sociedade mais democrática e inclusiva.

ABSTRACT. The changes that have taken place in the world of work in recent decades have reinforced the need to create a new type of worker. Education, in this context, is placed as an area of great strategic value and is singled out as both the cause and the solution to the problems inherent in the capitalist system. Business reformers, in their ambition to 'fix' education, convey a discourse that disqualifies the teaching practices - considered inefficient, and, at the same time, they formulate proposals of reforms that aim at the alteration of the own work of the professors and teachers; factors that undermine the identity of these professionals. Through a dialogue with important authors of the area of work and education the present study approaches the relation between the work and the constitution of the identities in the labor activities in general and the teaching in particular, besides indicating aspects of how the transformations in the world of work and the educational reforms of the last decades have induced changes in the identities of teachers and teachers; furthermore, it demonstrates how the reforms meet 
the interests of the hegemonic groups of contemporary capitalist society and against the interests of those who are guided by the construction of a more democratic and inclusive society.

\section{Introdução}

Entre o final do século $X X$ e o início do século $X X I$, nas sociedades capitalistas contemporâneas, têm ocorrido várias transformações no que se refere ao âmbito do trabalho. A reestruturação produtiva tendo por base os modelos de produção flexível, a introdução de novas tecnologias com a disseminação da informática e dos instrumentos digitais, novos padrões de gestão da produção e do trabalho, etc. Esses novos modelos de organização do trabalho e da produção, no entanto, não significam uma substituição total do modelo taylorista pelo modelo da produção flexível, mas antes uma recomposição entre os dois modelos. Essas mudanças, porém, estariam exigindo um novo tipo de trabalhador, o trabalhador multifuncional, aquele com grande capacidade de detectar e solucionar problemas, com grande capacidade de inovação e criatividade, mas desde que em prol dos interesses das organizações capitalistas: a maximização da produtividade e, logo, da acumulação.

Nesse contexto, a educação, cada vez mais, tem sido colocada como uma área de grande valor estratégico, sobretudo no que tange às demandas dos grupos hegemônicos dessas mesmas sociedades. Muitos dos problemas inerentes ao próprio sistema capitalista têm sido atribuídos, por esses grupos, à escola e aos educadores e, mais diretamente, ao trabalho dos professores. Ao mesmo tempo em que são responsabilizados pelo insucesso dos alunos e pelo fracasso da escola - mal formados, incompetentes, anacrônicos, ineficientes, omissos, descompromissados, pregadores de ideologias esquerdizantes, acomodados, eis algumas das acusações, os docentes convivem com o grande desprestígio da carreira, com os baixos salários, com o desrespeito por parte de vários outros atores envolvidos no processo educativo, com as condições de trabalho quase sempre precárias - vide a pouca atração que a profissão desperta nos estudantes egressos do ensino médio. E isso sem falar nos fatores extraescolares, tais como a realidade das comunidades nas quais se situa a maioria das escolas, as condições sociais e econômicas dos estudantes que as frequentam.

No discurso dos chamados reformadores empresariais, que se insinuam por meio de vários instrumentos de convencimento - tais como os conteúdos veiculados pela grande imprensa, a atuação de organizações empresariais, a ação de várias organizações não governamentais, as recomendações de organismos multilaterais como o Banco Mundial, percebe-se o ataque ao trabalho e à imagem dos docentes. E além disso, os reformadores 
propõem normas e regras para o trabalho dos professores que, em grande medida, significam a intensificação e precarização das atividades dos docentes tendendo a separar a concepção da execução, isto é, uma crescente taylorização do trabalho docente. Esse quadro tem propiciado abalos não só no trabalho dos professores e professoras como nas maneiras como eles e elas são vistos e também nas formas como se veem, ou seja, nas suas identidades.

Contrariando as perspectivas desses reformadores e mais afinado com as posturas de estudiosos e pesquisadores da educação que ambicionam que ela, de fato, cumpra suas finalidades sociais - não apenas a promoção do ensino e da aprendizagem, mas também da igualdade e da democracia - este texto procura discutir as relações entre trabalho e identidade, ou antes, como o trabalho funciona como um elemento identitário, principalmente no caso específico da docência (DUBAR, 1997; COUTINHO et. al, 2007; HYPOLITO, 1997; CIAMPA, 2001; CARDOSO, 2011; KADDOURI, 2009; SAVIANI, 2004) e, por fim, como as reformas educacionais têm atuado sobre o trabalho e as identidades dos docentes nas últimas décadas (APPLE, 2002; MASCARENHAS, 2002; OLIVEIRA, 2003; EVANGELISTA \& TRICHES, 2014).

Além dessa introdução, o texto é constituído de três partes. Na primeira seção discute-se a noção de identidade e sua relação com o trabalho. Na segunda, é abordado o trabalho docente e a construção das identidades dos professores e professoras. Na terceira seção são apontados aspectos das mudanças no mundo do trabalho, das reformas educacionais realizadas nas últimas décadas e a maneira como elas têm abalado as identidades dos docentes. No final, a título de considerações finais, são retomados, sinteticamente, os principais pontos do texto.

\section{Trabalho e identidade}

Partimos do pressuposto de que a identidade não é um dado, mas algo que vai se dando. De acordo com Ciampa (2001) ela é "uma totalidade contraditória, múltipla e mutável, no entanto una (...) sou uma unidade de contrários, sou uno na multiplicidade e na mudança" (CIAMPA, 2001, p. 61). A construção e a reconstrução contínua da identidade se dão numa dimensão individual e coletiva, na relação tensa e dialética entre as pessoas e delas com o contexto social e histórico em que vivem. Nesse sentido, não podemos concebê-la como uma 'essência' ou portadora de uma suposta autonomia em relação aos sujeitos humanos e às condições sociais e históricas em que eles vivem. A identidade é um constructo humanosocial-histórico. Ou melhor, a identidade é uma representação construída e reconstruída pelos seres humanos dentro de determinados contextos sociais e históricos. Kaddouri (2009) defende que "a identidade deve ser analisada como processo em perpétua construção, 
desconstrução, reconstrução. (...) um vir a ser cujo futuro se constrói constantemente" (KADDOURI, 2009, p. 24). Portanto,

não é possível dissociar o estudo da identidade do indivíduo do da sociedade, [pois] diferentes configurações de identidade estão relacionadas com as diferentes configurações da ordem social (...) é do contexto social e histórico em que 0 homem vive que decorrem suas determinações $e$, consequentemente, emergem as possibilidades e impossibilidades, os modos e as alternativas de identidade (CIAMPA, 2001, p. 72).

Cardoso (2011) opta, entretanto, por usar o conceito de identidade no plural, ou seja, identidades, pois assim considera a pluralidade dos sujeitos e das instituições sociais. Embora Ciampa (2001) utilize o termo no singular, suas proposições se aproximam das de Cardoso (2011) para quem as identidades são construções sociais e históricas, são produtos de um determinado contexto sociopolítico e não podem ser analisadas como uma 'essência' própria de um sujeito ou coletivo por toda a sua existência. Nesse artigo optamos, também, pelo uso do conceito na sua forma plural.

Mas, como é construída a identidade, ou melhor, as identidades? São construídas pelos grupos dos quais fazemos parte, fato que remete às relações que são estabelecidas entre os membros do grupo entre si e do grupo com o meio onde existe, pelas suas práticas, pelas suas atividades; e onde operam, evidentemente, aspectos da história, das tradições, dos valores, dos interesses, das regras e das normas. É um processo contínuo e dinâmico em que, sucessivamente, vamos nos diferenciando e nos igualando, conforme os vários grupos sociais de que fazemos parte (CIAMPA, 2001).

O conhecimento de si é dado pelo reconhecimento recíproco dos indivíduos identificados através de um determinado grupo social que existe objetivamente, com sua história, suas tradições, suas normas, seus interesses etc. (...) [E pelo fato de] ser a identidade constituída pelos grupos de que fazemos parte, faz-se necessário refletirmos como um grupo existe objetivamente: através das relações que estabelecem seus membros entre si e com o meio onde vivem, isto é, pela sua prática, pelo seu agir (num sentido amplo, podemos dizer pelo seu trabalho) (...) é pelo agir, pelo fazer, que alguém se torna algo (...) nós somos nossas ações, nós nos fazemos pela prática (CIAMPA, 2001, p. 64).

A noção de identidades que adotamos aqui comporta tanto a ideia de que são produzidas como a de que se constituem numa representação. A produção e a representação das identidades ocorrem por meio das atividades desempenhadas pelos sujeitos ou coletivos de sujeitos, em suma, pelo trabalho, e pelo trabalho situado em determinadas condições sociais e históricas.

Como no atual contexto mundial se modificam as formas de gestão da produção e dos trabalhadores, alteram-se também as relações interpessoais estabelecidas no campo do 
trabalho, o qual incorpora, para falar como Coutinho (et. al. 2007), modificações a partir da prevalência do valor econômico em sua definição e propósitos, apresentando características como precariedade, vulnerabilidade e fragmentação. Desse modo, identificar por intermédio do trabalho e construir identidades profissionais têm sido uma dificuldade, afirma Coutinho (idem) ao considerar que os processos identificatórios são determinados pelas condições a que o trabalhador vivencia. Se desempregado ou inserido no mundo informal do trabalho, o indivíduo passa a ter novas identificações resultantes de sua nova condição.

Para Dubar (1997) a construção da identidade se dá na infância e vai se reconstruindo ao longo da vida como produto de sucessivas socializações. Esse autor entende que a dimensão profissional é uma das múltiplas dimensões que definem a identidade do indivíduo. Uma vez trabalhador, há uma identidade social de empregado que acompanha as mudanças conforme elas se dão nas relações com o trabalho.

Poderíamos afirmar, então, que o homem - a humanidade - se produz e reproduz pelas suas atividades - entre as quais o trabalho, que é a atividade primordial e fundante -e é por meio delas que constrói suas identificações, ou seja, que se identifica para si e para os outros. Antes de qualquer outra coisa o homem é um animal, mas um animal social e histórico e em contínuo processo de hominização de si mesmo. Diferentemente dos outros animais o homem precisa agir sobre a natureza - pelo trabalho - tirando dela a sua sobrevivência. "Portanto, é pelo trabalho que os homens se produzem a si mesmos. Logo, o que o homem é, o é pelo trabalho. O trabalho é, pois, a essência humana" (SAVIANI, 2004, p.28). O modelo interpretativo do materialismo histórico - bem como suas principais categorias de análise à maneira como foram talhadas por Marx no século XIX - ainda é um referencial de peso, sobretudo nas ditas ciências humanas.

Em síntese, a definição do homem como o conjunto das relações sociais indica que o indivíduo se põe, na concepção marxiana, como um sujeito histórico e social. (...) 'o indivíduo só pode se tornar um homem se assimilar e incorporar à sua própria vida, à sua própria atividade, as forças, formas de comportamento e ideias que foram criadas pelos indivíduos que 0 precederam e que vivem ao seu redor' (MARKUS, 1974, p.88). Assim, o indivíduo só pode se constituir como homem e, nessa condição, como sujeito de seus próprios atos, nas relações cotidianas com os outros homens. Eis por que afirmei, (...), que em Marx a questão da subjetividade se manifesta como indissociável da intersubjetividade (SAVIANI, 2004, p. 41).

Trabalho e identidades estabelecem, dessa forma, uma relação orgânica e dialética. O homem é um animal social e histórico e em contínua e progressiva hominização de si mesmo e, por isso mesmo, não está limitado no seu vir-a-ser por um fim preestabelecido e nem está livre das condições históricas em que vive (CIAMPA, 2001, p. 71-72). Dessa maneira, a relação entre o trabalho e as identidades só pode ser analisada no bojo do movimento social, isto é, no contexto do processo histórico. "A História (...) é a história da 
autoprodução humana, o que faz do homem um ser de possibilidades, que compõem sua essência histórica" (Idem, p.68).

Todavia, se o homem só se faz homem pelo trabalho, e se é pelo trabalho que ele constrói e reconstrói suas identidades individuais e coletivas, o que dizer do trabalho de educar os homens? Sim, porque "o indivíduo da espécie humana não nasce homem; ele se torna homem, se forma homem. (...) para integrar o gênero humano ele precisa ser formado, precisa ser educado" (SAVIANI, 2004, p. 46). O que dizer, então, do trabalho dos professores e professoras?

\section{Trabalho docente e identidades}

Nas proposições marxianas, e mesmo naquelas reconhecidamente marxistas, o ponto inicial da análise parte ou partiu, quase sempre, da investigação sobre o trabalho fabril, isto é, o trabalho exercido pelos proletários nas indústrias. Esse fato favoreceu, em parte, certo distanciamento entre a docência e as demais atividades laborais. Tanto que vigoram ainda concepções que não consideram o ensino como um trabalho, embora, mais recentemente, sejam poucas. Entre muitos estudiosos e pesquisadores - e não só da área da educação existem várias divergências sobre a natureza e as especificidades do trabalho dos professores e professoras. É um trabalho produtivo ou improdutivo? Qual é o produto do trabalho docente? É um trabalho capitalista ou não capitalista? Deve ser enquadrado na produção, no setor de serviços ou no âmbito da circulação? Essas questões não se encontram no horizonte desse texto. Entretanto, compartilhamos com a concepção que toma o ensino como trabalho e, em função disso, consideramos que a atividade docente exerce, entre outras, também uma função identitária.

Os debates sobre o trabalho e identidade docente não são novos, mas nas últimas décadas, em função das grandes transformações no mundo do trabalho - reestruturação produtiva flexível, expansão das tecnologias digitais etc. - e das várias reformas educacionais em curso, as discussões envolvendo as questões educacionais - e dentro delas a questão do trabalho dos professores - ganharam uma enorme dimensão. A amplitude dos impactos dessas mudanças e reformas no trabalho dos professores e, logo, na sua identidade - ou identidades - torna-se uma questão relevante. Tecendo reflexões sobre a constituição das identidades na docência Cardoso (2011) argumenta que

as identidades profissionais dos docentes devem ser analisadas como um movimento, uma construção dinâmica, um processo contínuo, que pode conhecer fases de rupturas, de continuidades ou reelaborações a partir de modelos anteriores de identificação (CARDOSO, 2011, p. 188). 
Nesse sentido, o autor indica a permanência de certa representação da identidade dos professores e professoras ligada à imagem de sacerdócio, de missão, de uma função marcada pela ideia de vocação e a partir da qual se construiu uma noção da docência como que distanciada de qualquer ambição material (Idem, p. 189). A permanência dessa imagem dos docentes, de acordo com Hypolito (1997), decorre do fato de que o processo de constituição da escolarização regular e da profissão docente no contexto da formação do capitalismo deuse dentro do movimento de laicização da educação, isto é, da transferência para leigos de uma atividade que era desempenhada por membros da Igreja. $O$ autor sugere que os grupos mais conservadores procuraram manter a docência vinculada às ideias de sacerdócio e vocação, enquanto aqueles mais identificados com o liberalismo, ao defenderem a escola pública estatal, passaram a reivindicar um professorado mais técnico e profissional.

No caso brasileiro, no bojo do processo de superação do regime autoritário e de redemocratização do país, ocorrido entre o final dos anos de 1970 e a década de 1980, e com o crescimento das entidades organizativas do professorado, forjou-se a noção de 'trabalhadores do ensino', termo que, ao mesmo tempo, pretendia denunciar as condições precárias dos docentes e outros profissionais ligados à educação, mas que também favoreceu uma identificação dos professores e professoras com os trabalhadores em geral, sobretudo o operariado. Segundo Cardoso (2001):

Essa concepção buscaria romper com a lógica da abnegação, do sacerdócio, visto que as condições de trabalho e salariais são questionadas, evidenciando uma nova postura em relação à imagem que o docente constrói para si e para a sociedade (CARDOSO, 2001, p. 190).

Essas questões destacam como as identidades - individuais ou coletivas - não podem ser analisadas fora de um contexto social, político e histórico a partir do qual são construídas. É por isso que para se discutir as identidades docentes, como se constituem e se transformam, na atualidade, devemos levar em conta as grandes mudanças no mundo do trabalho e as reformas educacionais que se processam na educação desde as últimas décadas.

\section{Transformações no mundo do trabalho, reformas educacionais e as identidades docentes}

\subsection{Taylorismo e reestruturação produtiva flexível}

O mundo do trabalho, nas sociedades contemporâneas, tem sofrido intensas mudanças e adotado distintas configurações decorrentes, principalmente, de importantes 
transformações percebidas no contexto social como um todo. Os avanços tecnológicos, a expansão do trabalho assalariado no setor de serviços, a ampliação dos mercados financeiros globais, uma nova divisão espacial e internacional do trabalho, são alguns dos aspectos determinantes dessas transformações.

Com incalculáveis custos que afetam, diretamente, a vida das pessoas e a vida do planeta, essas transformações promovidas por um sistema capitalista globalizado reconfiguram a sociedade atual e aprofundam as desigualdades socioeconômicas. As políticas de cunho neoliberal que, sistematicamente, têm sido adotadas pelos países capitalistas, acarretam sérios problemas para a classe trabalhadora ao promover a perda, efetiva, dos seus direitos.

Além disso, ao reconfigurar o mundo do trabalho, da produção e do consumo, as mudanças passam a exigir um novo perfil do trabalhador. $O$ trabalhador deve ser, agora, "mais escolarizado, participativo e polivalente". De maneira sutil, essa reconfiguração da sociedade capitalista tem promovido uma nova forma de controle do trabalho no qual "trabalhador vigia trabalhador". Nesse processo, "os trabalhadores são constituídos como indivíduos, não membros de uma classe", ou seja, a classe trabalhadora se vê fragmentada e impedida de participar, integralmente, do processo do seu trabalho (planejamento, execução e resultados) (MASCARENHAS, 2002, p. 13).

A classe trabalhadora, além de ter sofrido mudanças em sua constituição, com uma diminuição importante do operariado industrial e com a expansão do setor de serviços, vivencia um grave processo de agravamento do desemprego. Essas são questões que repercutem, diretamente, na composição da identidade do trabalhador enquanto membro de uma classe e, portanto, repercutem, diretamente, na capacidade de discernimento, posicionamento e de ação mediante os conflitos e relações de poder (MASCARENHAS, 2002).

Como é próprio dos processos históricos, observamos que as transformações referentes ao trabalho e sua organização portam contradições e ambiguidades e, também, implicam em rupturas e continuidades. Sim, pois ao mesmo tempo em que se dissemina o modelo flexível, aspectos do modelo taylorista ainda persistem.

Na visão de Taylor, o homem poderia atingir rendimento máximo se controlado o seu trabalho de modo a executar no tempo mínimo, gestos rápidos. Propagando a ideia da dependência a regras, o taylorismo se guia pela ilusão da inexistência da necessidade reflexiva.

Surpreendente é detectar que o ideário taylorista não desapareceu dos espaços da fábrica, empresas e dos lugares em que o objeto do trabalho é dado nas relações humanas, em vista de que o trabalho no século $X X$ ganhou dimensão de automatização, quando no processo de reestruturação capitalista, em que o mundo se modificou nas múltiplas 
dimensões, sociais, culturais, econômicas e políticas, implicou também novas "alternativas de identidade" (CIAMPA, 2001) para o indivíduo situado nessa sociedade de múltiplas determinações cuja tendência é fazer do homem um "mero suporte do capital' (idem).

Apple (2002), também, ao analisar o taylorismo como estratégia de gestão, considera que esse modo de administração não chegou a ser totalmente bem sucedido na sua tentativa de controle do trabalho, pois provocou tensões, greves e formas de resistência pelos trabalhadores, contudo, suas práticas ideológicas para desqualificar os trabalhadores, racionalizar e intensificar o seu trabalho acabaram se fazendo presentes.

No serviço público, os reflexos da gestão do Estado, realizada com base nos princípios da administração empresarial, se mostram no direcionamento de mecanismos de controle dos profissionais, no aumento das exigências por resultados, na intensificação do trabalho, na subtração da autonomia, nos contratos precários e na instabilidade profissional. Nesse contexto, os professores não têm ficado à margem do controle exercido pelas reformas educacionais.

Todas essas questões afetam a construção da identidade do trabalhador, em geral, e do trabalhador docente, em especial. Inserida nesse contexto de transformações profundas, a área educacional, lócus de intensa disputa de poder e de interesses de classes, tem sofrido um intenso processo de reformas que, por sua vez, incidem, diretamente, no trabalho e na constituição das identidades docentes.

\subsection{Reformas educacionais e identidades docentes}

Para Oliveira (2003), nos anos 1960 houve forte influência do tecnicismo na educação em geral, resultando "na introdução dos princípios da Administração Científica do Trabalho ao sistema escolar" (p. 14). A inserção da administração científica ou a gestão por resultados derivada de princípios empresariais na gestão pública brasileira encontrou espaço quando a economia no Brasil sofria influências externas de ideários liberais capitalistas, que exigia mão de obra qualificada e atribuía às instituições escolares esse papel.

Mediante esses princípios tayloristas de governabilidade, a Educação se encontra sob um processo de tentativa de separação entre a concepção e execução do trabalho do professor. Paralelo a isso, coexistem formas de domínio e anulação de toda configuração de resistência. Por meio da gestão por objetivos, da sistemática de avaliações externas, do direcionamento do currículo - a influência sobre a profissão docente vai para além do diagnóstico, proposição ou exigência da eficácia no ensino. As reformas legitimam formas de controle, sejam através de diretrizes que se põem a observar sistematicamente o trabalho docente, ou no direcionamento do que lhes cabe ensinar, exaurindo o professor e intensificando seu o trabalho. 
A intensificação representa uma das formas mais tangíveis onde os privilégios laborais dos/das trabalhadores/trabalhadoras educacionais estão corroídos. Possui muitos sintomas, dos triviais aos mais complexos - que oscilam da não concessão de tempo, nem sequer para se ir à casa-de-banho, tomar um café ou descansar, a uma ausência total de tempo para um indivíduo se manter a par da respectiva área. Pode verificar-se a intensificação, de forma mais visível, no trabalho mental, no sentido crônico de sobrecarga de trabalho que aumentou ao longo do tempo. (APPLE, 2002, p. 32).

A intensificação do trabalho exige o desdobramento do professor na realização de uma diversidade de tarefas - preparação de material didático para o desenvolvimento nas aulas, correção de provas e exercícios, preenchimento de fichas de frequência, organização e condução da participação dos alunos em concursos e Olimpíadas (Matemática, Astronomia, Língua Portuguesa etc.) - embora não o qualifiquem para o trabalho em suas áreas, considera Apple (2002). Para ele a diversificação de exigências comumente se resume ao cumprimento de prescritos, e à ausência de tempo para o exercício intelectual de aprofundamento teórico sobre o que lhe compete ensinar "e têm, mais uma vez, de depender mais fortemente de ideias e processos fornecidos por 'especialistas" (APPLE, 2002, p. 33).

A intensificação também actua de forma a destruir a sociabilidade de trabalhadores/trabalhadoras não manuais. O lazer e a auto-orientação têm tendência a perder-se. A comunidade tem tendência a redefinir-se em torno das necessidades do processo laboral. Além disso, visto que quer o tempo, quer a interacção são raros, o risco do isolamento cresce. (APPLE, 2002, p. 32).

A diversidade e intensificação do trabalho docente, resultado das inúmeras tarefas que deve cumprir, compromete a construção de sua identidade, a qual, como vimos, se faz como construção coletiva. Oprimida tanto pelas condições insuficientes de trabalho, quanto pela intensificação das exigências à profissão, a classe docente se vê desarticulada e fragmentada. Essa desarticulação e fragmentação compromete a construção de uma identidade profissional, sólida, baseada no reconhecimento da especificidade e importância da profissão. Importância que, efetivamente, supera o imaginário da sociedade que encara o trabalho dos professores como mero treino de alunos para provas e concursos.

Oliveira (2003) considera as reformas educacionais como estratégias racionalistas, que estão sempre em transição e que podem influenciar o mundo material e o social, conforme são conduzidas as intervenções pelas pessoas. Sendo, então, a educação um veículo fomentador do progresso técnico e do desenvolvimento humano, o direcionamento das reformas educacionais tem seus objetivos adequados a determinados fins, de acordo com o período histórico.

No Brasil, por exemplo, as políticas educacionais do início do século XX legitimadas na Constituição de 1934, responsabilizaram o Estado pela instrução pública e gratuita de uma 
população analfabeta que povoou as cidades. No período correspondente à Ditadura Militar tempo em que o ideário capitalista teve condições de propagação na justificativa de combate ao comunismo e restabelecimento da democracia - as reformas tendiam à qualificação da classe trabalhadora tendo em vista o ideário liberal de preparação para a produção capitalista. Já, com a Conferência Mundial sobre Educação para Todos, de 1990, realizada em Jomtien na Tailândia, os países participantes firmaram acordo da democratização da educação com princípio para o desenvolvimento e equidade social, estabelecendo uma nova gestão pública com base na descentralização administrativa e financeira.

Portanto, por trás de uma reforma, há sempre uma intencionalidade que a linguagem e sua expressão não revelam. Fato é que por trás das estratégias de uma política educacional que impetra o reconhecimento de um profissional, pode estar omissa a intenção de sua pacificação e tentativa de seu condicionamento. Outras vezes, as reformas não conseguem alcançar a efetiva concretização a que tencionam. "Por perseguir, em geral, a otimização dos recursos disponíveis por meio de maior racionalidade administrativa, a reforma muitas vezes aparece como matéria técnica, elaborada por peritos no assunto" (OLIVEIRA, 2003, p. 21).

Não raro, os especialistas, reformadores educacionais, são ligados a grandes grupos empresariais que alocam suas diretrizes nos documentos que elaboram. Essa ação pode ser entendida como o bônus obrigatório de credor àqueles que ficam sob seus condicionamentos. O Banco Mundial tem essa regra ao aplicar fomento a um país. Sob a justificativa de cooperação internacional - quando na verdade os princípios se aproximam de desenvolvimento econômico - junto com a verba, estão as condicionalidades de uma visão capitalista de projeto neoliberal. Oliveira (2003) assegura que a partir da Conferência de Jomtien, as reformas educacionais não só no Brasil, mas, na América Latina passaram a objetivar a distribuição da renda entre a população em condição de vulnerabilidade social. Contudo, esse propósito demandava investimentos para a expansão do ensino culminando em "estratégias de gestão e financiamento, que vão desde a focalização das políticas públicas e sociais ao apelo ao voluntarismo e ao comunitarismo" (OLIVEIRA, 2003, p. 23-24).

Baixando custos, controlando as políticas implementadas, a nova gestão pública fezse visando estabelecer parcerias e a "equidade far-se-ia presente, sobretudo nas políticas de financiamento, a partir da definição de custos mínimos assegurados para todos. No caso brasileiro, o FUNDEF é a melhor explicação dessa política" (OLIVEIRA, 2003, p. 24).

Nesse quadro de reformas, os professores se tornam os maiores responsáveis pela garantia da qualidade pretendida por elas, recaindo sobre eles a responsabilidade por resultados.

Uma contradição não raramente observada é que as reformas são de caráter imediato e não acompanham com a mesma urgência as alterações nas condições de trabalho dos professores, tampouco na estrutura que dê condições para as exigências impostas por elas. Insatisfeitos e cientes dos parcos resultados em níveis quantitativos, os professores assumem 
a responsabilidade para si, se encarando como inequívocos agentes de mudança. O Estado sabe disso ao implementar as reformas educacionais, apregoando a responsabilidade pelo seu fracasso aos professores. Não bastasse isso, os docentes têm que desempenhar funções que vão desde assistente social a enfermeiro, confirmando elementos que garantem a perda da identidade profissional.

Tais exigências contribuem para um sentimento de desprofissionalização, de perda de identidade profissional, da constatação de que ensinar às vezes não é o mais importante". [...] Nesse contexto, a desqualificação sofrida pelos professores nos processos de reforma que tendem a retirar deles a autonomia, entendida como condição de participar da concepção e organização de seu trabalho, aliada à desvalorização desses docentes - pela negação e desprezo pelo seu saber profissional -, contribui para o fortalecimento da sensação de mal-estar desses professores (OLIVEIRA, 2003, p. 33).

Nesse cenário, Evangelista e Triches (2014) comungam das ideias de Oliveira (2003). Para elas, a visão de organismos internacionais e associações não governamentais consideram a educação como responsável pela transformação da sociedade, no entanto, só recai sobre o professor a assumência dos fracassos que, em suma, se dão em função de outros fatores, tais como, as condições precárias de trabalho e a infraestrutura das escolas. Além disso, a formação, em grande parte, é custeada pelo próprio professor. Esquematicamente, ao se relacionar as exigências para a dedicação do professor com as reais condições de trabalho, a correspondência certamente não é biunívoca.

Paradoxalmente, o apelo ao professor não significa sua valorização social,
mas sua desqualificação nos planos discursivo e material. Compóe tal apelo
a ideia de ausência - estaria ausente no professor mais vontade de ensinar;
capacidade de refletir sobre sua prática; boa formação inicial; mobilização;
investimento na formação continuada; implementar a política
governamental... a lista das incapacidades do professor elencadas pelos
reformadores é longa. Não raro, estão ausentes dessas preleções as
condições materiais do trabalho e da existência do professor
(EVANGELISTA; TRICHES, 2014, p. 72).

Nos documentos dos Organismos Multilaterais (Banco Mundial, Organização das Nações Unidas para a Educação, a Ciência e a Cultura - UNESCO, Conselho Nacional de Secretários da Educação - CONSED entre outros) depreende-se em seus slogans a certeza de que a educação garante a redução da pobreza e desenvolve o país.

Ao transformar as relações de trabalho, gerenciando-as sob os pressupostos capitalistas os resultados desse gerenciamento ecoam sobre a formação da identidade docente, a qual é constituída a partir dos vários papéis que os docentes exercem na sociedade, seja pela fala, pelo lugar de pertencimento, pela atribuição e auto retribuição feita pelos outros. O contato social se responsabiliza de construir a identidade de cada ser. Sendo 
assim, a identidade pode ser negada e reconstruída diante das adversidades constituintes das relações humanas.

Desta forma, o engajamento consciente num projeto político recobre a questão da identidade, considera Ciampa (2001), sugerindo que a inserção em intentos que concorrem para a hominização do ser constitui ato histórico que transforma as condições de existência, devendo ser enfrentada por todos.

Sem posicionar o homem nos extremos limitantes entre a objetividade (coisificado) e a subjetividade, ou pura consciência, a concepção para o engajamento segundo Ciampa (2001) recobre não patologizar a contradição, nem a mudança, porque identidade é movimento e transformação.

\section{Considerações finais}

O campo da educação é, em função de sua grande importância estratégica no mundo contemporâneo, lugar de intensas e tensas disputas que envolvem suas finalidades e objetivos, suas configurações e estratégias, seus conteúdos, currículos, sistemas de avaliação e, claro, o trabalho de professoras e professores.

No quadro das transformações mais recentes no mundo do trabalho, a escola e os professores têm sido solicitados a se adequarem às 'novas' demandas requeridas pelo sistema capitalista. Os grupos hegemônicos, por meio do discurso reformador, procuram impor reformas educacionais afinadas com os seus interesses e segundo as quais os docentes devem ser responsabilizados pelos resultados escolares. Os reformadores, inclusive, têm proposto várias normas e regras prescritas para o trabalho dos docentes.

A efetivação dessas reformas, no entanto, tem contribuído para a intensificação e precarização do trabalho, além de reduzirem a margem de autonomia dos professores em relação à execução de seu trabalho; fatores que, indubitavelmente, estão gerando fortes abalos no trabalho e, logo, nas identidades dos professores e professoras.

É evidente que compartilhamos da importância da escola e dos professores para a vida social. Porém, não podemos restringir e condicionar os resultados do processo educativo apenas ao trabalho dos docentes e, muito menos, aos interesses de apenas alguns grupos dentro do contexto de toda uma sociedade.

Aqueles que defendem a construção de uma sociedade mais justa, mais igualitária e democrática - entre os quais nos incluímos - reconhecem o caráter dinâmico da vida social, contudo, preconizam que a natureza de qualquer reforma não deve ser no sentido de ampliação das possibilidades da acumulação capitalista, mas na direção de uma sociedade mais humanitária e onde todos os atores possam ter como horizonte a plena realização das suas potencialidades individuais e coletivas, pois, afinal, são fatores determinantes na construção das identidades. 


\section{Referências}

APPLE, Michael W. Controlar o trabalho docente. Proletarização: classe e gênero. In: APPLE, Michael W. Manuais escolares e trabalho docente: uma economia política das relações de classe e gênero na Educação. Lisboa: Didáctica Editora, 2002. p. 26-62.

CARDOSO, Maurício Estevam. Identidade(s) docente(s): aproximações teóricas. In: OLIVEIRA, Dalila A.; PINI, Mônica E.; FELDFEBER, Myriam. (orgs.) Políticas educacionais e trabalho docente - perspectiva comparada. Belo Horizonte: Fino Traço, 2011. p. 187-213.

CARVALHO, M. M. C de. Reformas da Instrução Pública. In: LOPES, E. M. T; FARIA FILHO, L. M de; VEIGA, C. G. (org). 500 Anos de Educação no Brasil. 2 ed. Belo Horizonte: Autêntica, 2000. (Coleção Historial, 6).

CIAMPA, A. da C. Identidade. In: LANE, S. (org.). Psicologia social - o homem em movimento. São Paulo: Brasiliense, 2001. p. 58-75.

COUTINHO, Maria Chalfin et al. Identidade e trabalho na contemporaneidade: repensando articulações possíveis. Psicologia \& Sociedade; 19, Edição Especial 1, p. 29-37, 2007.

DUBAR, Claude. A socialização: construção das identidades sociais e profissionais. Portugal - Porto: Porto Editora, 1997.

EVANGELISTA, Olinda; TRICHES, Jocemara. Professor: a profissão que pode mudar um país? In: EVANGELISTA, Olinda (org.). O que revelam os slogans na política educacional. Araraquara-SP: Junqueira \& Marin, 2014. p. 47-82.

HYPOLITO, Álvaro L. M. Trabalho docente, classe social e relações de gênero. Campinas: Papirus, 1997.

KADDOURI, Moktar. Dinâmicas Identitárias e relações com a formação. In: BRITO, Vera L. F. A. de (org.). Professores: identidade, profissionalização e formação. Belo Horizonte: Argumentum, 2009. p. 23-44.

OLIVEIRA, Dalila Andrade. As reformas educacionais e suas repercussões sobre o trabalho docente. In: OLIVEIRA, Dalila Andrade (org.). Reformas educacionais na América Latina e os trabalhadores docentes. Belo Horizonte: Autêntica, 2003. p. 13-37.

SAVIANI, Dermeval. Perspectiva Marxiana do problema subjetividade-intersubjetividade. In: DUARTE, N. (org.). Crítica ao Fetichismo da individualidade. Campinas-SP: Autores Associados, 2004. p. 21-52.

TAYLOR, Frederick W. Princípios da administração científica. Disponível em: <http://portaldoconhecimento.no.comunidades.net>. Acesso em: 12 jun. 2016. 